\title{
O persuasor permanente entre a solidão e o alinhamento: o processo de profissionalização da sociologia na Argentina e a construção de um campo intelectual (1955-1966)
}

\author{
The permanent persuader between loneliness and alignment : the process of \\ professionalization of sociology in Argentina and the construction of an \\ intellectual field (1955-1966)
}

\section{Alexandra Dias Ferraz Tedesco ${ }^{1}$}

RESUMO

O presente artigo tem como objetivo problematizar a constituição de um campo intelectual acadêmico, a partir do processo da institucionalização da Sociologia na Argentina, numa perspectiva que leva em conta as vicissitudes formais e epistemológicas das tensões que emergem no mundo intelectual argentino no momento imediatamente posterior à queda do peronismo (1955). A partir da análise da circulação das propostas dos sociólogos que encampam esse projeto, notadamente do ítalo-argentino Gino Germani, o intuito é pensar a emergência da figura do intelectual acadêmico como sujeito salutar nessas disputas e, notadamente, problematizar uma questão sensível desse processo: as dinâmicas, sempre fluídas, entre posições de autonomia e posições de engajamento. Consideramos, para tanto, uma discussão que visa conectar a análise dos intelectuais com sua problematização sociológica, compreendendo a ação e as tentativas de ação desses indivíduos dentro de uma disputa conjuntural por definir as fronteiras desse novo campo e, nesse sentido, projetarem-se como interlocutores propositivos da interpretação do peronismo, querela que polariza e mobiliza a circulação de ideias naquele contexto.

Palavras-chave: Peronismo. Sociologia argentina. Gino Germani. Campo intelectual. História intelectual.

\footnotetext{
${ }^{1}$ Graduada e Mestre em História pela Universidade Estadual Paulista Julio de Mesquita Filho, com ênfase na área de História e Cultura Política. Doutoranda do Programa de Pós Graduação em História da UNICAMP (2013-2019), desenvolve pesquisa vinculada à linha de Cultura Visual, História Intelectual e Patrimônios, sob orientação da Prof. Dra. Silvana Barbosa Rubino. A pesquisa recebe financiamento do Conselho Nacional de Desenvolvimento Científico e Tecnológico, CNPq.
} 
This article aims to discuss the establishment of an academic intellectual field, from the sociology of institutionalization process in Argentina, and from a perspective that takes into account the formal and epistemological vicissitudes of the tensions that emerge in the Argentine intellectual world at the moment immediately after the fall of Peronism (1955). From the analysis of the circulation of the proposed sociologists who materialize this project, especially the Italian-Argentine Gino Germani ,the intent is to think the emergence of the academic intellectual figure as subject wholesome in these disputes and, notably, to question one sensitive issue of this process: the dynamic, ever flowing, between greater autonomy and engagement positions. We consider, therefore, a discussion that aims to connect the analysis of intellectuals with their sociological questioning, including the action and attempts to action of these individuals within a cyclical struggle to define the boundaries of this new field and, accordingly, to project themselves as propositional interlocutors interpretation of Peronism, quarrel polarizing and mobilizing the flow of ideas in that context.

Keyword: Peronism. Argentine sociology. Gino Germani. Intellectual field. Intellectual history.

"Nenhuma sociedade pode se queixar de seus intelectuais, pois ela só tem os que faz"

Sartre-Em Defesa dos Intelectuais, 1994.

Aqueles que observam, sob olhar retrospectivo e documental, os reclamos de institucionalização contidos nas atas de fundação do Departamento de Sociologia da Universidade de Buenos Aires, em 1957², podem facilmente imaginar a existência de uma demanda clara de profissionalização que emerge com o fim do peronismo em 1955. Apesar do tom direto e programático de seus idealizadores, contudo, o processo de reorganização da Universidade de Buenos Aires e, principalmente, da Facultad de Filosofia y Letras, nos leva necessariamente a algumas tensões de grande porte - tensões que ultrapassam a discussão acerca da renovação epistemológica pretendida pelos intelectuais que se reincorporam a Universidade após uma década de marginalização institucional -, algumas das quais pretendemos abordar neste artigo.

Embora alguns nomes de proa do processo de renovação, tais como Gino Germani3 e José Luis Romero ${ }^{4}$, estejam direta e justamente vinculados a esse processo de renovação, a função dos intelectuais e

\footnotetext{
2 Esses reclamos podem ser consultados nas Atas Anuais da Universidade de Buenos Aires (Biblioteca Ricardo Levene), enquanto os Boletíns del Instituto de Sociologia encontram-se agrupados na Biblioteca de la Facultad de Ciencias y Letras da Universidade de Buenos Aires (anos 1943 -1948)

3 O italo-argentino Gino Germani, considerado um dos pais fundadores da sociologia argentina, atuou como investigador na Universidade de Buenos Aires entre 1942 e 1946 sob a supervisão de Ricardo Levene e, no contexto que abordamos, após 1955, atuou como um dos nomes fundamentais do processo de reorganização dessa Universidade, tendo a seu cargo a estruturação do curso de Sociologia.

4 José Luis Romero foi um destacado historiador e intelectual argentino, conhecido principalmente por sua atuação na modernização da pesquisa histórica na Universidade a partir da divulgação das perspectivas analíticas em desenvolvimento na França nos anos 1950 e 1960.
} 
seus espaços de atuação pública são um polo de tensão que remonta à própria criação da Universidade de Buenos Aires, ainda no século XIX5, e que não se resolve, por decreto, no ato de "libertação da universidade", simbolizado pela entrega da reitoria da UBA a uma figura de prestígio no campo cultural argentino, como Romero. Se o peronismo foi capaz, por um lado, de criar uma adesão indistinta de opositores através da interdição da autonomia universitária e da consequente alocação dos professores proscritos em instâncias privadas, essas adesões não se sustentam após a queda do regime, e a rápida politização do campo universitário após 1955 pode exemplificar essas tensões.

Para Silvia Sigal, em Le rôle politique des intellectuels, o fim do primeiro peronismo, em 1955, é marcado por uma expectativa de liberdade e de contato com a modernidade por parte dos intelectuais. Esse otimismo, contudo, ao ser convertido num necessário esforço de entendimento e reorganização, não é capaz de se sobrepor às tensões que germinaram, no campo intelectual, durante a década peronista. Assim, o período que vai de 1955 a 1957 é marcado por uma paz de curta duração, rompida drasticamente quando o presidente Frondizi decreta a permissão das universidades privadas e ou confessionais, frustrando assim as expectativas de amplos setores da universidade. ${ }^{6}$

Além das vicissitudes do processo de reorganização institucional, é preciso matizar a atuação dos protagonistas desse processo. Gino Germani e José Luis Romero, entre tantos outros, dificilmente podem ser descritos como defensores irrestritos da autonomia universitária tal qual a imaginamos contemporaneamente. Não se trata, neste artigo, de tentar um juízo de suas trajetórias, pelo contrário, trata-se de analisar o sentido das disputas por autonomia protagonizadas por eles dentro do espaço cultural argentino de finais da década de 1950.

Após longos anos de intervenção, o objetivo de resguardar o espaço universitário enquanto local de produção acadêmica não exclui, a priori, a colaboração e heteronomia em relação ao novo governo, principalmente no período que vai de 1955 a 1957, primeiros momentos da reorganização institucional das universidades argentinas. O fato de que o novo governo estivesse disposto a garantir a segurança desse espaço universitário, portanto, não assegurava de imediato sua soberania irrestrita, como o demonstram os esforços de "normalização" institucional. Lembramos, nesse sentido, o alerta de Sapiro que, ao analisar o campo literário francês, observa que "toda etapa de autonomização suscita uma nova forma de dependência" (SAPIRO, 2004, p. 101) e que, dessa forma, pensar as reivindicações por autonomia em termos absolutos torna-se contraproducente.

Além das dificuldades propriamente referentes à reorganização universitária, a ideia de "desperonização" também trazia tensões adicionais. Autores como Sigal (1996), Neiburg (1997) e Fiorucci (2011), Blanco e Jackson (2014), demonstram que não houve consenso sobre a forma que poderia dar-se esse processo. Muitos dos desacordos baseavam-se, inclusive, nas interpretações distintas acerca do peronismo.

\footnotetext{
5 A Universidade de Buenos Aires tem seu primeiro estatuto, promulgado pela Ley Avellaneda, em 1885, embora tenha se originado da fusão de diversas instituições isoladas, processo que teve início em 1880.

${ }^{6}$ Nesse sentido, Sigal destaca que o apoio à presidência de Frondizi se constituiu como um demarcador de fronteiras dentro da Universidade. Enquanto a maior parte dos professores alinhadas ao processo de reorganização universitária apoiou a proposta do conhecido "presidente letrado", amplos setores, especialmente discentes, desconfiavam da proposta de modernização de Frondizi, principalmente no que dizia respeito ao financiamento externo de pesquisas. (SIGAL, 1996).
} 
Enquanto alguns setores mais liberais - como aqueles reunidos em torno da Revista Sur - não o compreendiam senão enquanto um evento nefasto na política argentina, outros setores, notadamente a partir de uma perspectiva sociológica, começavam a projetar uma explicação estrutural para o fenômeno. Outros ainda, como a salutar revista Contorno, começavam a problematizar a responsabilidade dos próprios intelectuais no processo. ${ }^{7}$

Para além desses debates intelectuais, o processo de interdição do peronismo é também tumultuado nas associações gremiais, no movimento estudantil e nas repartições públicas. Para Rubinich (2015, p. 2), nesse sentido, as tensões que envolvem os protagonistas universitários, nesse contexto, "ubican a estos agentes bastante lejos del perfil del académico tradicional y los acercan a lo que la tradición occidental del ultimo siglo conoce como intelecutal". Essa correlação estreita, portanto, entre a reorganização política e a reorganização universitária, entre prestígio acadêmico e espaço de intervenção pública nos remete, por fim, a um tópico clássico da história intelectual argentina: em fins da década de 1950, posicionar-se teoricamente sobre o peronismo era posicionar-se sobre a própria Argentina. Como o demonstra Neiburg (1997), participar da discussão sobre o peronismo era fundamental para legitimar não apenas o debatedor, mas os próprios espaços culturais em que se davam essas contendas.

É a partir da problematização acerca desse "lugar de fala", amplamente instável na Argentina, que observamos a perenidade do debate sobre o papel do intelectual diante da política ao longo de um século de intervenções e disputas de prestígio. Oscar Terán, em Ideas em el Siglo, recorda que se remontarmos à geração dos 80 , veremos a discussão sobre o papel do intelectual já como eixo norteador e definidor das fronteiras no campo cultural. No contexto da virada do século XIX para o século XX, a questão imigratória proporciona um espaço de legitimidade salutar para os intelectuais na arena pública, qual seja, uma função cívica, de "limitar los efectos de anomia a los recién llegados" (TERÁN, 2004, p. 17). Nas primeiras décadas do século $X X$, a difusão do positivismo nas letras argentinas e uma concepção bastante específica de progresso e destino civilizatório contribuíram para uma "tematização exacerbada" da questão nacional, ao passo que colaboraram também para a consolidação de um campo autônomo para o intelectual que se dispunha a entrar na celeuma sobre o "ser argentino". Esse espaço público, contudo, esteve muito mais radicado no periodismo do que propriamente na Universidade, circunstância que já nos apresenta uma das dicotomias fundamentais que constituirá a pauta da discussão da segunda metade do século XX: a fissura entre o intelectual científico e o intelectual escritor, hegemônico nas primeiras décadas do século, representante de uma "cultura estética [...] que avanzaría en sus pretensiones de hegemonia sobre el campo intelectual" (TERÁN, 2004, p. 29).

Pela exiguidade do espaço, contudo, não pretendemos abordar de forma sistemática essas primeiras disputas pela criação de um campo autônomo de atividade intelectual. Consideramos, contudo, que para entender essas disputas que dizem respeito à condição do intelectual, especialmente do sociólogo, no recorte que pretendemos abordar (1955 - 1966), é fundamental levar em conta que a tensão entre autonomia, engajamento e interferência política não é uma novidade para os atores sociais argentinos do

7 Uma exposição canônica sobre a Revista Contorno nesse processo pode ser encontrada em Monegal (1956). 
tumultuoso contexto do fim do peronismo ${ }^{8}$, na mesma medida em que os sentidos práticos desses reclamos por liberdade de ensino e de pesquisa também não são virtualmente os mesmos.

A proposta deste artigo, dessa forma, é analisar o processo de criação de um campo autônomo de produção intelectual universitária atrelada ao processo de dessacralização do intelectual que perpassa o clima da reconstrução e, em alguns casos, destruição, da memória peronista. Trata-se de uma tentativa de dimensionar o impacto da fundação do Departamento de Sociologia e do curso de graduação em Sociologia nas discussões acerca da planificação econômica e modernização cultural que emergem na segunda metade da década de 1950 em toda a América Latina e, especialmente, na Argentina. Para tanto, nossa chave de acesso será uma discussão também ela bastante recorrente e controversa: os conceitos de autonomia e engajamento.

Partimos, também, da ideia de que se trata de um tema constantemente revisitado, e que se trata, nesse momento, de repensar a circularidade desse debate, a permanência dessas distensões conceituais, procurando encontrar nelas os indicativos de algumas tensões resilientes, que aproximam a experiência argentina de outros processos análogos no continente.

Constatada a impossibilidade de pensar esse processo a partir da análise de práticas lineares, procuramos problematizar essas matizes a partir de duas tentativas conceituais de apreensão do problema: a problematização de Edward Said acerca do papel do intelectual, dentro da universidade, como contestador, e as ponderações de Pierre Bourdieu acerca do modus operandi inscrito nas lutas pela definição das fronteiras e da autonomia dos campos intelectuais. A escolha dos dois autores passa pela possibilidade que suas propostas abrem de pensar que a disputa por autonomia no contexto da reestruturação da universidade argentina não é um dado bruto, tampouco se dá por um ato de vontade. Outrossim, é preciso pensar que tipo de reclamo prático está contido no projeto de reorganização universitária. Assim, mais do que cotejar os "graus" de autonomia, nos interessa pensar: autonomia em relação a que? Ao estado, que sustentava, nesse momento, um discurso apaziguador e integrador? Ao mercado editorial, debilitado durante o governo peronista e iniciando um momento de expansão de larga monta, capitaneado, no caso universitário, pelas novas editoras ligadas às publicações acadêmicas? Aos pares universitários, num contexto em que se debatia abertamente os limites do financiamento público de pesquisa? Consideramos que a confrontação das propostas dos autores nos possibilita pensar num híbrido entre engajamento e autonomia, onde se encontra, precisamente, a historicidade das interpretações sobre o peronismo e das lutas que se projetam a partir delas.

Inicialmente pode parecer contraproducente invocar o sociólogo francês Pierre Bourdieu para uma discussão nesses termos já que, como se depreende de uma parte considerável de seus textos mais metodológicos, a teoria não é um massa amorfa que se possa mobilizar como justificativa de estudos empíricos, mas sim uma reflexão que se inscreve nas próprias operações de pesquisa. É mister, portanto, evitar, em seus termos, "que o saber sociológico possa aparecer como uma soma de técnicas ou como um

\footnotetext{
${ }^{8}$ A história da Universidade de Buenos Aires, embora marcada por uma tradição de autonomia de gestão que está na base de seus estatutos de fundação, não é unilinear. Ao longo da década de 1930, por exemplo, o pres. Uriburu já havia executado uma intervenção de larga monta na universidade. Sobre isso ver Donghi (2012) e Buchbinder (1997).
} 
capital de conceitos, separados ou separáveis de sua utilização na pesquisa" (BOURDIEU; CHAMBOREDON; PASSERON, 2004, p. 13). Assim, conjugar uma análise do processo de institucionalização da sociologia na Argentina com a reflexão em torno de algumas categorias sondadas por Bourdieu em suas pesquisas sobre o campo francês não tem, nesse artigo, um caráter comparativo, sequer reivindicatório. Tem, outrossim, o intuito de atuar como vigilância epistemológica, um retorno ao "mesmo reflexivo", uma atenção, em suma, às práticas intelectuais tais como se apresentam em sua feitura, em sua dinâmica histórica, e não no seu resultado final. Reiteramos, dessa forma, sua advertência de que

[...] é necessário submeter a prática científica a uma reflexão que, diferentemente da filosofia clássica do conhecimento, aplica-se não à ciência já constituída, ciência verdadeira em relação à qual seria necessário estabelecer as condições de possibilidade e de coerência ou os títulos de legitimidade, mas a ciência em vias de fazer-se (BOURDIEU; CHAMBOREDON; PASSERON, 2004, p. 17).

Se Bourdieu é reivindicado aqui, dessa forma, não como paradigma, mas como impulso crítico, não é diferente o auxilio que buscamos na obra de Said ${ }^{9}$. Pensando as reivindicações por autonomia de forma polissêmica, Said nos ajuda a pensar uma relação dinâmica entre esses reclamos profissionais e uma noção de "responsabilidade" do intelectual, que conecta nossa discussão a um tópico fundamental desse debate que permeou a cultura universitária do ocidente a partir dos anos 1960. Afinal, autonomia pode ser entendida tanto como o oposto à heteronomia no sentido de independência como também, em sua concepção mais moderna, como o correlato negativo da ideia de engajamento político partidário. Considerando que são zonas problemáticas e nem sempre claramente diferenciadas, Said nos ajuda a pensar as diversas tonalidades que pode adquirir essa noção de engajamento, tanto enquanto responsabilidade para com a sociedade em que o intelectual está inserido, quanto enquanto responsabilidade para com sua própria prática de pesquisa.

Pensando no momento de produção das obras e em sua capacidade de circulação a nível internacional $^{10}$, é interessante perceber, além de algumas referências comuns, como Michel Foucault, que ambos encontram-se situados numa posição salutar dentro de seus respectivos círculos de produção simbólica. Ambos tiveram muita ressonância em suas áreas específicas, constituíram discursos de referência no espaço público e, por esse motivo, além do teor crítico de suas obras, sua trajetória como intelectuais nos

\footnotetext{
9 O crítico literário Edward Said aparece nessa discussão a partir de um referencial importante. Embora professor de universidades prestigiadas dos EUA como Harvard e Yale, nasceu em Jerusalém, numa família cristã. Ademais, criado entre Jerusalém e a cidade egípcia do Cairo, Said sempre se posicionou enquanto partícipe da causa palestina.

${ }^{10}$ No que diz respeito a Said, além de circular por diversas universidades prestigiosas, tanto como estudante como quanto professor (Princeton, Havard e John Hopkins, entre outras), publica em 1978 sua obra seminal "Orientalismo: o oriente como invenção do Ocidente", que teve ampla repercussão mundial a partir de sua edição inglesa, em 1979, tendo sido traduzido para diversos idiomas, inclusive o hebraico. Bourdieu, por outro lado, começa a lecionar no Collége de France também nos primeiros anos da década de 1980 e publica O Poder Simbólico em 1998, também amplamente traduzido.
} 
parece significativa para pensar a circulação das ideias a partir de um ponto de vista concreto, que dimensione a efetividade do discurso a partir das suas condições de enunciação.

Assim, portanto, situamos o esforço desse texto como um exercício de reflexão, onde as respostas sobre questões pontuais tendem a ser menos esclarecedoras que as perguntas, na medida em que essas ultimas nos possibilitam localizar as fissuras e as zonas híbridas que compuseram os debate sobre a institucionalização da carreira de Sociologia na Universidade de Buenos Aires, bem como os efeitos desse processo nas disputas pelo espaço do intelectual na arena publica argentina.

Ao pensarmos nas relações sociais e políticas que embasam a discussão sobre o papel do intelectual na esfera pública somos colocados diante da dificuldade inerente a esse tipo de escolha: tomar por objeto um mundo do qual se faz, ainda que indiretamente, parte, exige questionar o próprio pertencimento, as próprias filiações e a posição dentro de um campo que pretendemos questionar. Na busca dessa capacidade de autoobjetivação, partimos da prerrogativa específica de uma história intelectual que procura compreender não apenas a circulação das ideias em si - correndo o risco de pensa-las de forma desencarnada - mas também a forma de circulação dessas ideias, levando em conta as demandas políticas e as tensões sociais que encontram-se na zona fronteiriça da atividade intelectual.

Embora o que hoje se delimita como campo específico da história intelectual não esteja circunscrito a uma abordagem única, é interessante observar que os contornos gerais desse campo de pesquisa emergem na esteira de uma renovação da história política que se inicia no fim dos anos 1970 e início dos anos 1980. Segundo Altamirano (2007, p. 10), nesse sentido, história intelectual emerge dentro de um contexto de "erosão da ideia de um saber privilegiado". É justamente no fim da década de 1970, no momento de dessacralização da figura do intelectual diante dos movimentos sociais que emergem então, que se torna viável compreender o intelectual de forma objetiva e objetivada ${ }^{11}$.

Nas palavras sintéticas de Sirinelli (apud REMOND, 1996, p. 232)., trata-se de "um campo aberto, situado no cruzamento das histórias política, social e cultural" Embora aparentemente uma tentativa de definição tão ampla não nos ajude a delimitar o espaço específico dessa narrativa da história, ela é fundamental ao apontar a pluralidade de vertentes que a compõe, e contribuir para renovar e ampliar as possibilidades de pensar o espaço público. Tal renovação, que passa pela reavaliação da narrativa biográfica e chega ao limite em sua discussão linguística, foi fundamental para que se passasse a pensar os fatos do discurso como chave de acesso a um mundo social que é simbólico, e, portanto, parte da reivindicação de "uma história política sensível às dimensões simbólicas da vida social" (ALTAMIRANO, 2007, p. 13).

Apesar de sua reconhecida especificidade, as dificuldades de produzir história intelectual não são poucas, principalmente no que diz respeito, justamente, aos necessários critérios de objetivação do sujeito

\footnotetext{
${ }^{11}$ De acordo com uma vasta gama de analistas da figura e da função do "intelectual" no mundo contemporâneo, dentre eles Jean Paul Sartre, o conceito "intelectual" não pode ser desvinculado de sua historicidade. Adotamos, nesse sentido, a perspectiva que que embora os philosophes do século XVIII já compartilhassem de características que posteriormente foram sintetizadas no conceito de intelectual, até a década de 1970 sua ação e a repercussão de sua fala ainda se davam a partir de uma situação de prestígio específicas, condição essa que será paulatinamente questionada a partir de maio de 1968 e dos movimentos de ação direta que emergem na década de 1960 em todo o mundo ocidental, principalmente a Revolução Cubana.
} 
pesquisador. Jean François Sirinelli classifica essa dificuldade na metáfora da síndrome do mineiro, uma situação na qual a abundância de documentos - e a intencionalidade da produção dos mesmos - pode acabar se convertendo num empecilho metodológico. Embora nos posicionemos, para os fins desse artigo, numa hipótese oposta à do filósofo Norberto Bobbio no que diz respeito à definição do intelectual strictu sensu, nos vale seu alerta de que "falar dos intelectuais como se eles pertencessem a uma categoria homogênea e constituíssem uma massa indistinta é uma insensatez" (BOBBIO, 1997, p. 9). Partindo portanto das fissuras estruturais dentro do campo intelectual, o elemento de complexidade se torna uma característica constitutiva de toda a análise.

Além das dificuldades mais eminentes técnicas, há ainda a discussão acerca da interpretação do texto pelo contexto ou contexto pelo texto, que movimentou grande parte das discussões ao longo da década de 1980 e 1990. Para Lacapra (1992, p. 429), nesse sentido, pensar a natureza dessa relação complexa deve ser o foco mesmo do método da história intelectual. Além disso, emergem também as questões ligadas aos pertencimentos nacionais e as história cívicas, de onde muitas vezes se projetaram os intelectuais na arena pública, especialmente no caso argentino.

O contexto que pretendemos abordar trás ainda complexidades adjacentes no que diz respeito à questão nacional. Como salienta Donghi (2012), o processo político que se inicia em 1943 e se concretiza em 1946, com a eleição de Juan Domingo Perón, entra em choque com uma tradição universitária bastante específica, no caso da universidade de Buenos Aires. ${ }^{12}$ Já em novembro de 1943 o início do processo de intervenção na Universidade abria caminho para a proposta que o governo peronista encamparia nos anos seguintes: a universidade deveria ajudar os argentinos a pensarem-se como argentinos e, nesse sentido, a autonomia de gestão e pesquisa sequer é um ponto de pauta. Embora as relações internas, especialmente na Facultad de Filosofia y Letras, não tenham sido substancialmente alteradas num primeiro momento, o governo peronista deixava claro, com a nomeação de Tomás Casares para o cargo de interventor, que "concebia su mision (da universidade) como la de reeducar por la vía autoritária la adormecida ciencia argentina" (DONGHI, 2012, p. 135). Algumas medidas como a implantação do ensino católico obrigatório e a orientação para que a universidade cumprisse seu papel de "definir una cultura apoyada en princípios absolutos, los de la verdadeira filosofia y la doctrina revelada y en elementos contingentes aportados por el 'suelo, estirpe, tradición e história" (DONGHI, 2012, p. 140) nos indicam a monta do processo de desmanche da autonomia universitária, que havia sido uma prerrogativa fundacional da UBA ${ }^{13}$.

Embora nosso recorte se paute no processo específico da Universidade de Buenos Aires, a orientação peronista sobre a universidade não se restringiu a ela, muito pelo contrário, no caso de Córdoba, foi ainda

\footnotetext{
12 Com "tradição específica" queremos destacar a importância dos debates sobre autonomia universitária que remontam à Reforma de 1918, iniciada na Universidade de Córdoba. As relações de tensão entre o campo político e o universitário, a partir desse ponto, não se configuram pacíficas, tampouco a intervenção peronista foi a primeira a confrontar a tradição reformista. Sobre as intervenções anteriores, especialmente no governo do general Uriburu, ver Fiorucci, Blanco e Sigal.

${ }^{13}$ É importante considerar, nesse ponto, que o movimento da Reforma Universitária, iniciado em Córdoba em 1918, é o ponto de inflexão nas demandas por autonomia em toda extensão das universidades argentinas. Embora não problematizaremos aqui esse processo, os reclamos por autonomia de pesquisa e participação estudantil nas deliberações internas tiveram um alcance continental, e não podem ser perdidos de vista.
} 
mais direta ${ }^{14}$. Em discurso de 1947, nesta universidade, Perón supõe que "ellas (universidades) existen tan solo para enseñar, aprender y realizar investigaciones cientificas adecuadas. Otros factores no deben intervenir en ellas. Pretendemos eliminar totalmente la politica de la Universidad"15 e, no caso de alguma ambivalência referente às possibilidades de autonomia universitária, inclusive no âmbito das tomadas de posição pessoais de professores e alunos, Perón conclui afirmando que "más que la fictícia independência y autonomia, debe existir una autonomia espiritual y moral que es superior a todas las demás"

Muito embora, ao longo do governo peronista (1945 - 1955), a UBA tenha experimentado momentos de normalização, o clima de politização crescente de diversos setores da universidade (especialmente do movimento estudantil) contribuiu para que a instância da universidade fosse vista como um problema político para o novo governo, análise em que concordam Ana Germani (2004), Donghi (2012) e Buchbinder (1997). A ideia de que toda a produção intelectual deve contribuir tecnicamente a partir de uma estrita neutralidade, embora não incida diretamente sobre a organização interna dos cursos universitários da Facultad de Filosofia y Letras, acaba contribuindo para a criação de uma expectativa autoritária, sensação reiterada por diversos de seus protagonistas em olhar retrospectivo.

Além desse cerceamento subjetivo, um terço dos professores da Universidade perde suas cátedras nesse contexto. Alguns francamente perseguidos pelo governo, outros renunciando em coro com um movimento estudantil radicalizado e paulatinamente clandestino. A Ley 13031, de 1947, atrelava a Universidade à gestão estatal, provocando a saída de mais de mil docentes de seus cargos, a maior parte deles através de renuncias e aposentadorias (BUCHBINDER, 1997).

Alguns autores, como Donghi (2012) e Buchbinder (1997), nos lembram, contudo, que os anos peronistas não foram de estagnação total, como quer fazer crer uma parte da historiografia. Como pontua Guido Riccono (2012, p. 10), "la Universidad de oro de 1955 a 1966 sólo es entendible en su contraposición a la Universidad de las sombras de 1945 a 1955, no a una explicación o fundamentación rigurosa de los hechos que en este período tuvieron lugar". Diversas bolsas foram concedidas e alguns aportes financeiros importantes foram executados, muito embora "en la situación de la universidad peronista, los académicos, emudecen ante el conflito y dejan de sentir próprio el espacio que les é más natural" (RICCONO, 2012, p. 12).

Diante dessa situação de descontinuidade entre a autonomia e o engajamento, condições tão subjetivas e, em nosso contexto, tão paradoxais, consideramos que algumas discussões que aparentemente não pertencem por natureza à história intelectual podem nos ajudar a pensar essas tensões. Importa, em nosso caso, reconhecer o campo de produção privada como o grande catalisador das discussões e da produção cultural que se davam na margem da universidade. Assim, de muitas formas, os reclamos por autonomia no fim do peronismo são salutares, pois, em alguma medida, inauguram um esforço inédito de fazer da universidade o local por excelência do pensamento. Se, conforme Sapiro, todo processo de autonomização engendra novas vinculações, a discussão que se segue, levando em conta as leituras de Said

\footnotetext{
${ }^{14}$ Segundo dados de Buchbinder, no ano de 1946 foram levadas a cabo intervenções nas mais prestigiosas universidades do país, como a Universidad de Cordoba, a Universidad de La Plata, a Universidad del Litoral, a Universidad de Tucumán e a Universidad de Cuyo, além da própria Universidad de Buenos Aires.

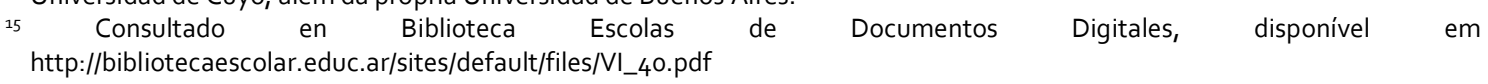


e de Bourdieu, não pode necessariamente partir de uma divisão a priori entre "política" e "ciência", mas sim de uma zona híbrida onde se negociam diversos tipos de prestígio, tanto pessoais quanto institucionais.

A relação que os homens de letras, como profissionais e detentores de monopólios culturais específicos, mantiveram com a esfera política pode ser assim compreendida dentro de um quadro amplo, que conecta o problema argentino a uma questão definidora do que costuma se entender como "modernidade". Quando essa disputa pelo espaço público aparece pela primeira vez de forma amplificada, no caso Dreyfus, em 1884, já é possível localizar algumas das discussões acerca do ator "intelectual" como protagonista da fala crítica na arena pública. Já estamos diante, nesse contexto, da pluralização das instâncias de consagração típica do crescimento urbano e do aumento do número de letrados nas cidades, condição que colocará diante dos homens de letras a necessidade de defender-se enquanto campo. Essa defesa se dará, via de regra, pela consolidação de uma série de relações de prestígio intrínsecas às instituições.

No contexto argentino, é importante frisar, mesmo nos momentos de intervenção da universidade e politização de sua gestão, mantiveram-se "zonas de autonomia" (TERÁN, 2004). Fora da Universidade, circuitos independentes como o Colégio Livre de Estudos Superiores (grande aglutinador dos intelectuais que saíram da universidade no período peronista), e as livrarias, salões, publicações importantes como a Revista Contorno e editoras (notadamente a Abril e Paydós) que proliferavam na Argentina desde a década de 1930, forneciam um espaço de circulação de ideias extrínseco à Universidade, que durante muitos anos disputou com ela os instrumentos de concessão de prestígio e a possibilidade de falar em nome dos "intelectuais". Como nos lembra Buchbinder (1997, p. 14), "en la Argentina existió siempre un activo mundo ligado a la producción intelectual y cultural que se mantuvo fuera de los âmbitos académicos y cuyos vínculos variavan a lo largo de este siglo $(X X)^{\prime \prime}$.

Essa situação de ambiguidade, nesse sentido, é um ponto de inflexão para pensarmos de que forma as disputas internas dentro das instituições universitárias é também sintomática de um conjunto mais amplo de discussões, que envolve, no limite, o próprio papel do intelectual diante da cena da cidade moderna.

Wolf Lepenies, na obra As Três Culturas, mostra como as disputas epistemológicas em torno das interpretações histórica e sociológica da modernidade constituem, via de regra, uma exacerbação de uma tensão política mais profunda, relacionada em ultima instância ao conflito ilustração $X$ anti-ilustração, que define, no limite, o papel dos intelectuais na gestão do mundo contemporâneo. Para ele, é no momento em que a sociologia se institucionaliza e que seus intelectuais se projetam no espaço publico que é possível identificar uma disputa pela "primazia de fornecer a orientação chave da civilização moderna, o direito de ser a doutrina de vida apropriada à sociedade industrial" (LEPENIES, 1996, p. 11).

É contando com essa complexidade inerente à tentativa de mirar o instrumento de crítica contra a própria crítica, que consideramos que as análises sobre a autonomia e o papel público do intelectual levadas a cabo pelo historiador Edward Said e pelo sociólogo e filósofo Pierre Bourdieu podem nos ajudar a cotejar o problema das condições de enunciação de determinados discursos que emergem em nosso contexto. Acreditamos que pensar a realidade argentina fora de seus termos clássicos pode jogar luz sobre um ponto 
importante, qual seja, a modernização da atividade intelectual em termos de circulação concreta de prestígios e obras, diante de uma ampliação substancial do público leitor e de uma crescente profissionalização da atividade intelectual.

Nossa hipótese passa pela ideia de que pensar o engajamento e a profissionalização como movimentos dicotômicos do mesmo processo (que é típico da modernidade e do ocidente e, portanto, pode e deve ser pensado sob um referencial holístico) pode constituir uma chave de acesso fundamental ao problema argentino, na medida em que os rompimentos e as continuidades que se operam no seio da reconstrução da UBA e da institucionalização do curso de Sociologia não são processos restritos ao âmbito teórico das escolhas epistemológicas, mas estão necessariamente vinculados aos novos horizontes que a consolidação da sociologia trás para as disputas no campo intelectual.

Além disso, perscrutando a discussão entre Said e Bourdieu é possível, ainda, dimensionar a celeuma teórica entre uma perspectiva histórica ligada à cultura clássica e ao papel clássico do intelectual como descortinador e uma perspectiva pragmática, ligada a essas novas possibilidades analíticas que representam a sociologia da modernização, especialmente na América Latina.

Sabemos que pensar o problema da autonomia do campo intelectual argentino durante o peronismo é, há muitos anos, um tópico clássico da historiografia sobre o tema, principalmente devido à onda memorialística que vem trazendo a tona diversos depoimentos e memórias sobre o período. Compartilhamos, contudo, do alerta de Edward Said, quando diz que ao mesmo tempo em que devemos nos preocupar com a censura totalitária, não podemos ser complacentes com um sistema "democrático" de pesquisa que favorece o alinhamento e prejudica o dissidente. Pela atualidade da discussão e pelas fissuras até hoje visíveis no campo intelectual da sociologia argentina, partimos para uma análise de foco conceitual para, em seguida, confronta-la com os dilemas específicos de nosso recorte.

Pretendemos, dessa forma, tentar um diálogo entre as equidistantes discussões de Edward Said e Pierre Bourdieu a partir de uma perspectiva diacrônica, que possa contribuir para a problematização dos seguintes aspectos tensionais do estudo dos intelectuais: a ligação entre campo acadêmico e campo político, o engajamento e o amadorismo como estratégias de resistência e autonomia, os limites da ação individual do homem de letras e, por fim, a relação do intelectual com a instituição e dessa com a sociedade na qual inserida.

A atuação do intelectual em arenas não circunscritas a universidade foi e é conflituosa em diversas culturas. Projetar-se no espaço público, para alguns interpretes, é um dever do homem de letras, que exerce essa função na sociedade e não deve deixar de cumpri-la a custo de descaracterizar-se. Para outros analistas, no entanto, o engajamento público aparece mais como uma traição à ciência e, nesse sentido, à própria causa intelectual. Exemplo desse segundo ponto de vista, para Norberto Bobbio a relação dos intelectuais com o poder é circunstancial, e não é viável pensar uma definição de intelectual em termos de engajamento já que, para ele, "a história das ideias e a história das ações correm sobre trilhos paralelos que raramente se encontram" (BOBBIO, 1997, p. 17). 
Said aborda essa questão ao lembrar as análises de Antonio Gramsci e Julien Benda. Para Benda os intelectuais traem a cultura quando fazem política, inclusive pelo fato de impedirem a originalidade do discurso daqueles que não fazem parte do campo intelectual ${ }^{16}$. Para Gramsci $(1982$, p. 7), pelo contrário, é preciso uma abordagem mais extensiva do conceito de intelectual, na medida em que "todos os homens são intelectuais, poder-se-ia dizer; mas nem todos os homens desempenham na sociedade a função de intelectuais".

O pensador italiano nos lembra, nesse sentido, que embora muitas vezes os homens de letras se considerem autônomos em relação ao grupo social dominante, não é possível entende-los fora do quadro das relações sociais. Tal condição manifesta-se, por exemplo, no fato de que "o circulo critica de modo colegiado e contribui assim para elaborar os trabalhos dos redatores individuais, cuja operosidade é organizada segundo um plano e uma divisão do trabalho racionalmente pré-estabelecida" (GRAMSCl, 1982, p. 120).

Independentemente do ponto de vista pelo qual se observe essa tensão, nos parece fundamental encontrar zonas híbridas de ação entre a solidão e o alinhamento, entre a autonomia total e o engajamento cego. Se fizermos um exercício de método e procurarmos trazer essa discussão para a análise do campo argentino, poderemos nos surpreender com a distancia entre o que os intelectuais do Instituto de Sociologia na década de 1950 foram e o que, de fato, pretenderam ser. Nessa linha fronteiriça, relativizar o engajamento não é o mesmo que nega-lo, outrossim se configura um exercício de crítica, capaz de observar a função pública do intelectual no marco de uma divisão do trabalho e do prestígio específicas, históricas e observáveis sistematicamente.

Diante desse ponto de tensão sobre o engajamento e papel público do intelectual que são constitutivas das dinâmicas culturais da modernidade, Said propõe em Representações do Intelectual, uma postura de amadorismo, capaz de garantir a efetividade do intelectual no espaço público a partir de uma posição autônoma, que viabilizasse o exercício de sua função por excelência: falar a verdade ao poder. Para ele, a audiência não está lá para ser satisfeita, mas sim para ser provocada, na esteira de uma longa tradição de engajamento que remonta ao próprio Sartre e aos existencialistas franceses ${ }^{17}$. Nessa seara, somente "quando se rebela o especialista se torna um intelectual" (SARTRE, 1994, p. 7), extrapolando a função social (e técnica) e, na afirmação clássica do existencialista francês, intervém em esferas a que não foi chamado.

Sua defesa do amadorismo, contudo, pode e deve ser observada a partir da objetivação de sua própria posição dentro do campo. Said, tensionado entre duas vinculações importantes, foi capaz de realizar esse trânsito, muito embora vinculado, ao longo de toda sua vida, à instância universitária. Segundo a leitura de Bourdieu a postura de "amateur" só pode ser compreendida dentro da instância do campo de produção simbólica, na medida em que esse intelectual "desinteressado", amador, faria coro, em ultimo grau, a um

${ }^{16}$ A postura de Benda, já bastante estudada, pode ser analisada também sob o ponto de vista de uma forte tendência conservadora de reclusão aristocrática da elite letrada, encampada principalmente pelo pensador espanhol José de Ortega y Gasset.

${ }^{17}$ É importante considerar, todavia, que embora as definições acerca do intelectual como agente que extrapola sua função técnica são comuns nos olhares de Said e de Sartre, este último não vê a transformação do técnico em intelectual como uma ação ligada à um voluntarismo individual, mas sim a ve atrelada à uma gama de condições sociais favoráveis à esse processo. Sobre isso ver Sartre (1994) e Nizan (1960). 
discurso utópico, que ignora o poder do hábitus nos limites de ação dos indivíduos submetidos aos jogos de prestígio de determinado campo.

Para o sociólogo francês toda interação no campo "produce y supone una forma específica de interés (las prácticas cientificas no aparecen como desinteresadas sino por referencia a intereses diferentes, producidos y exigidos por otros campos)" (BOURDIEU, 2009, p. 76). Isso ocorre, segundo Bourdieu, porque quem fornece reconhecimento ao intelectual são seus pares e, nesse sentido, não faz sentido apelar a uma autoridade externa ao próprio campo, como parece sugerir a figura do amador de Said.

Esse é um ponto que toca diretamente a especificidade do campo intelectual argentino. Como indicamos anteriormente, grande parte das redes de prestígio e de circulação cultural na argentina se dava, até a década de 1960, num circuito de recrutamento bastante restrito, composto por intelectuais que nutriam relações familiares e compartilhavam de um ethos bastante específico, fundado em relações de mecenato privado. A noção de defesa da cultura, do exílio interno e de sobrevivência da liberdade enquanto prática individual é uma das apostas mais recorrentes veiculadas por essa concepção extra-acadêmica de intelectual. Tal situação, aliada às sucessivas intervenções na Universidade, fomentou uma ampla rede de escritores e artistas diletantes e, em certa medida, defensores da postura do "amateur" como garantia de liberdade de expressão. Nessa direção, Sigal aponta que, resultado dessa configuração paradoxal das instâncias de consagração amadoras, a dependência da universidade e sua recorrente submissão às oscilações políticas "ont contribué à consolider la capacite d'auto-organisation des intellectuels" (SIGAL, 1996, p. 102).

Quando Said, notadamente a partir da obra Orientalismo (1978), questiona algumas das amarras que percebe nas posturas ideológicas e falsamente epistemológicas da intelectualidade europeia, o foco de sua análise recai no papel e na responsabilidade públicas do intelectual, que, em sua concepção, deve agir como um perturbador e não como um reprodutor dos discursos (SAID, 2007). Estaria esse homem de letras inserido na esfera pública porém longe dos dogmas, mantendo os olhos abertos às inúmeras naturalizações que sobrevém das instituições enunciadoras da verdade, do poder. Segundo ele, são os intelectuais os responsáveis por questionar o próprio sistema de produção e circulação da cultura, ou seja, os responsáveis por direcionar os aparelhos analíticos contra si mesmos, objetivando-se, conforme propunha Bourdieu.

Nesse sentido, pode ser útil pensar, conforme o sociólogo francês, na existência de estruturas objetivas e subjetivas que orientam nosso olhar sobre o mundo. Dentro dessa margem de atuação do sujeito, a observação mais eficaz é aquela que objetiva o sujeito da objetificação, ou seja, aquela que procura destituir o sujeito observador de seu privilégio e submete-lo à crítica que leva em conta, sua origem social, sua trajetória institucional, seu gênero "enfim, os pressupostos constitutivos da doxa geralmente associados à Skholé" (BOURDIEU, 2001, p. 20). É preciso, pois, refletir sobre os limites de pensamento e sobre suas condições de exercício: "repudiar os vestígios de moralismo religioso ou político, que servem de inspiração subterrânea à inúmeras interrogações de aparência epistemológica" (BOURDIEU, 2001, p. 12).

Para pensar essa tensão e traze-la para o centro da análise é imperativo retê-la como objetivação, como prática de circulação e troca, como "lógica específica de um campo que se institui em estado 
incorporado sob a forma de um habitus específico, ou melhor, de um sentido do jogo, ordinariamente designado como um 'espírito' ou um 'sentido' que praticamente jamais é posto ou imposto de maneira explícita" (BOURDIEU, 1989, p. 21). Dessa forma, não seria viável nutrir uma postura utópica, onde a autonomia do intelectual surgiria de uma espécie de vocação messiânica, outrossim, a possibilidade de atuação livre estaria precisamente na constatação da historicidade do habitus do campo intelectual, de onde poderia vir, a partir do olhar crítico, a possibilidade de autonomia intelectual.

Segundo Bourdieu (1989, p. 171), diante do processo de "autonomização progressiva do sistema de relações de produção, circulação e consumo dos bens simbólicos" a função ou a garantia da função do intelectual passa a funcionar como o próprio princípio unificador desse campo. Justamente, portanto, no momento de sua dessacralização, torna-se o campo consciente da necessidade de defender-se e, de acordo com a lógica das homologias de classe, passar então a produzir para os produtores, fomentando a existência de campos de admiração mutua. Certamente trata-se de um diagnóstico dificultador para a ação autônoma no campo público, inclusive porque, ao posicionar-se enquanto interlocutor político e submeter-se a critérios de validação extrínsecos, "a intervenção do grande público chega a ameaçar a pretensão do campo ao monopólio da consagração cultural" (BOURIDUE, 2001, p. 107).

A partir dessa divergência entre os dois autores, no entanto, é possível compreender de forma contínua uma necessidade de crítica que aproxima as duas propostas. Said, ao fim e ao cabo, fala em uma relativa independência do intelectual, enquanto Bourdieu localiza na objetivação do sujeito observador uma dessas possibilidades de olhar desnaturalizado ${ }^{18}$. Resta ainda, contudo, um ultimo ponto a ser abordado: a questão do profissionalismo do intelectual, criticada por Said, e as relações institucionais que permeiam sua relação com o espaço público.

Para Said, é preciso enfrentar a política estando nela. Não seria, dessa forma, a universidade, ou a skholé de Bourdieu, instituições que condenam os intelectuais a uma eterna subserviência, mas sim o modo de produção da cultura que se estabelece dentro delas, permeado por uma duvidosa e meritocrata política de cátedras e pela especialização cada vez maior que caracteriza os centros de pesquisa. A saída para essa situação contraditória, para Said, consistiria numa aposta de risco individual, na construção de um ponto de discurso outsider, representado por ele pela figura do exilado que estaria, pela fragilidade dos laços institucionais, mais apto a uma análise de risco, menos submissa, obtendo assim uma posição de equilíbro entre o olhar institucional e a ação autônoma e pessoalmente desinteressada daquele que "fala a verdade ao poder". Segundo ele, "o exílio nesse sentido metafísico é o desassossego, o movimento, a condição de estar sempre irrequieto e causar inquietação nos outros" (SAID, 2005, p. 60). Sempre em busca de uma sorte de efeito desestabilizador, a condição da margem libera da necessidade de cautela.

Essa "condição de margem", embora passível de ser entendida como aquele rol de atividades nãocentrais ao desenvolvimento de determinado campo científico, é também, como salienta Bos (2008), portadora de um potencial subversivo. A própria ideia de "margem", nesse sentido, deixaria implícita uma adesão, não uma exclusão. Pensando nesses termos, o marginal estaria em condições mais profícuas tanto

${ }_{18}$ Ou, conforme aponta em Meditações Pascalianas, na esteira de Pascal, proceder a um "cancelamento da ambição do fundamento" (BOURDIEU, 2001, p. 9). 
para efetuar exercícios de crítica quanto para, num caso limite, operar as chancelas necessárias ao "centro", ao que não se vê como marginal.

Para Bourdieu (2001), por outro lado, existe um risco nas visões iluministas que enxergam o homem de letras a partir da ideia de vocação. Para ele, esse tipo de análise pode incorrer na "ilusão do dom", a partir da qual enxergar-se acima das vinculações estabelecidas pelo habitus de cada campo pode acabar em um "aristocracismo, que deve seu sucesso ao fato de oferecer aos habitantes do universo escolástico uma perfeita teodiceia de seu privilégio" (BOURDIEU, 2001, p. 36). Não deve permanecer invisível ao intelectual, portanto, a lógica de sua própria prática. Para Bourdieu (2001, p. 82), há uma ignorância da diferença de acesso à esfera pública e à fala pública de forma geral. Isso relaciona-se diretamente aos distintos graus de capital escolar do sujeito. Essa ideia fere "o universalismo intelectualista, que está no âmago da ilusão escolástica" (BOURDIEU, 2001, p. 83), como se a aptidão à escolha correta estivesse na essência humana, e não fosse derivada de "condições históricas para a emergência da razão".

Assim cairia por terra por ingênua a proposta de autonomia de Said, ainda que como autonomia relativa, pois o intelectual não existe como vocação, num sentido iluminista, mas sim enquanto indivíduo inserido num habitus específico e que opera dentro dele como o instrumento da própria reprodução do campo. É a partir dessa posição no campo, homóloga ao campo político e econômico, que o sujeito desenvolve estratégias de melhora na sua posição relativa no campo e, nesse sentido, talvez falar a verdade ao poder não seja exatamente uma estratégia atraente, ao menos no que diz respeito à sobrevivência do próprio campo, da qual depende a força das adesões individuais.

Em Campo del poder, campo intelectual y habitus de classe (2009), Bourdieu nos dá algumas pistas sobre como balancear essa autonomia de Said, ao afirmar que muito da visão messiânica e sacralizada do intelectual decorre de uma análise baseada no "mito criador [...] que tiene por princípios u anristocratismo de la inteligência y una representación carismática de la direción y de la reprodución de las obras simbólicas" (BOURDIEU, 2009, p. 25). Segundo ele, esse tipo de análise, inclusive, seria a grande responsável por uma leitura "encantada" da prática intelectual, que a visualiza acima das determinações de possibilidades do campo, ignorando sua condição contraditória de fração dominada da classe dominante (BOURDIEU, 2009, p. 30).

Certamente as duas perspectivas tem muitos pontos em comum, principalmente no que diz respeito ao instrumento da crítica como ferramenta imprescindível para o posicionamento público do intelectual. Capaz de desfazer naturalizações e historicizar a própria posição daquele que enuncia o discurso, a objetivação é, na visão de ambos, um imperativo para manter em vista as relações de opressão que estão por trás dos discursos e, principalmente, para evitar a universalização de posições que são, sobretudo, históricas. Apesar dessa concordância essencial, os autores nutrem posições distintas no que diz respeito às possibilidades de vocação para a autonomia do sujeito intelectual. A discussão conceitual nos leva, por fim, à uma ultima indagação: que contribuições essa discussão pode trazer para pensar a história intelectual? E, principalmente, que auxílio essa discussão nos pode prestar para refletir acerca das tensões do momento de reestruturação da Universidade de Buenos Aires, nos primeiros anos da década de 1950? 
Quando José Luis Romero é designado interventor da Universidade, nos primeiros meses do novo regime, em 1955, torna-se perceptível o vulto do processo de reorganização que se encontrava por fazer. Ao mesmo tempo em que não se pretendia perdoar aqueles que, por alguma razão, haviam permanecido na Universidade nos anos anteriores, não era viável ignorar a dificuldade de estabelecer novos critérios de admissão que pudessem dar conta dessa triagem de forma isenta ou, ao menos, institucionalmente legítima ${ }^{19}$.

Elaborado ao longo de três anos - entre 1955 e 1958 - o novo Estatuto Universitário começa a vigorar e, com ele, propostas concretas de modernização universitária. Enriquecem-se aportes financeiros, inicia-se um processo sério de internacionalização e, principalmente, no que diz respeito ao nosso recorte, subsidia-se e incentiva-se a criação de novos cursos, alinhados com esse espírito de renovação.

É nesse contexto que a organização dos cursos de Psicologia, Ciências da Educação e Sociologia é levada a cabo. No caso do Curso de Sociologia, a cargo do professor Gino Germani, o incentivo é francamente institucionalizado. O reitor Frondizi em pessoa, segundo documentação biográfica de Ana Germani, viajou aos Estados Unidos em 1957 para angariar fundos junto à fundação Ford, no intuito de viabilizar os aportes técnicos do novo Departamento (GERMANI, 2004, p. 144).

A criação do Departamento de Sociologia ocorria, dessa forma, em paralelo à um processo de renovação bastante amplo, que tinha base na universidade mas que perpassava uma ampla gama de instituições e tradições culturais ${ }^{20}$. A pauta central do campo intelectual era, naquele contexto, a "questão peronista", ou, mais precisamente, qual seria o papel reservado aos operários e à pequena classe média diante do fim do regime. Ligado à essa questão, postulava-se ainda a ideia de uma "recuperação institucional", sob forma de uma ampla modificação nos quadros do funcionalismo público que possibilitasse uma real "desperonização" da sociedade ${ }^{21}$.

O esforço por "desperonizar" as instituições, portanto, dava a tônica desse processo de reconstrução, alinhado à percepção dos renovadores de que a Universidade deveria trabalhar para essa refundação nacional, fomentando o desenvolvimentismo e contribuindo para a criação de uma burguesia técnica qualificada, que pudesse constituir o substrato humano dessa Argentina moderna que se queria ver surgir. Um panorama extremamente favorável, como veremos, para a proposta de sociologia que será levada a cabo no novo departamento.

Embora a Universidade de Buenos Aires já contasse com cadeiras de sociologia desde fins do século XIX, tratavam-se de cursos obrigatórios nas carreiras centrais de Direito e de História. Contudo, a existência

\footnotetext{
19 Uma alcunha que aparece algumas vezes nos depoimentos sobre o período é ilustrativa dessa questão. Trata-se dos "professores flor de cebo", aqueles que permaneceram na universidade sob intervenção peronista.

${ }^{20}$ As mais diversas tendências e alinhamentos que compuseram a base de apoio ao movimento de 1955 são representadas, em termos de produção cultural, na publicação de diversos artigos e livros e na realização de conferências sobre o tema do peronismo. Protagonistas desses debates destacamos aqui Mario Amadeo, Jorge Sabato e Jorge Luis Borges.

${ }^{21}$ O decreto 3855, de 1956, é ilustrativo desse processo, na medida em que cria diversos dispositivos jurídicos para a "desperonização", dentre a proibição do proselitismo na universidade.
} 
desses cursos não se configurava como uma atividade orgânica já que eram, muitas vezes, ministrados por profissionais de outras áreas, interessados ou diletantes nos "estudos sociais".

Em sua obra Historia de la Facultad de Filosofia y Letras, Buchbinder (1997) parte para um levantamento programáticos desses cursos, oferecidos para os alunos do quarto ano dos cursos de História e Direito. Ainda em 1899, sob comando do prof. Antonio Dellepiane e, após sua morte, sob orientação do prof. Ernesto Quesada, a proposta era uma disciplina de síntese entre a filosofia e a análise social. Baseado numa análise histórica do pensamento social, o curso era marcado pelas influências de Comte, Spencer, Mill e Gobineau. Mesmo após 1911, quando a Cátedra passa a ser dirigida pelo professor (e historiador) Ricardo Levene, o programa ainda girava em torno de uma "história do pensamento social", embora contenha, já ai, algumas discussões metodológicas que serão aprofundadas por Gino Germani, a partir de 1956.

Na obra "La Sociologia em América Latina", que reúne escritos gestados entre 1953 e 1956 e que vem a público no momento em que Gino Germani estava, precisamente, atuando enquanto estruturador do Departamento de Sociologia, é possível perceber os contornos da nova orientação do curso que estava nascendo. A proposta de Germani, ao fim e ao cabo, intencionava pensar o "novo sociólogo", que viria substituir o mero aficionado, não profissional e pouco afeito às especificidades requeridas pela prática sociológica. No limite, trata-se de estabelecer um "novo nível de competência", de controlar a pesquisa de forma clara, com investimentos claros e partir de critérios de transparência acadêmica, quais sejam

[...] la critica escrita en las revistas especializadas, la selección del personal para los cargos de enseñanza, investigación o practica professoral, los títulos académicos reconocidos por las organizaciones cientificas y, por fin, la reputación misma dentro de la comunidade de sociólogos (GERMANI, 1966, p. 2).

Se retomarmos a análise de Bourdieu, perceberemos, de forma pungente, a intenção de estruturação de um campo autônomo para a sociologia que estava sendo pensado a partir da fundação do novo Departamento. A proposta de definir os limites da prática de pesquisa e atividade docente, e de inserir essas práticas em uma rede estruturada de "aceitação pelos pares" pode ser inserida dentro do anseio de profissionalização da atividade intelectual mesma, em oposição às instâncias de consagração extrínsecas à Universidade que, durante a década peronista, configuraram o espaço de prestígio da intelectualidade portenha.

O projeto, contudo, não é simples. Germani diagnostica uma tendência bastante arraigada no modus operandi do pensamento social no continente. Para ele, inicialmente o pensamento latino-americano esteve focado na definição das nações, influenciados por Hegel, normalmente com analises feitas por literatos. Dentre os nomes clássicos dessa visão essencialista do social estariam figuras de grande prestígio nas letras argentinas como Echeverria, Alberdi e Sarmiento. Germani via nessa tendência uma inclinação a perceber a 
sociedade como dado a partir de um profundo sentido de continuidade histórica que, segundo ele, contribuía para obscurecer a análise. Essa situação pode ser verificada quando observamos rapidamente a proposta bibliográfica dos cursos de sociologia anteriores a 1955, a grande maioria delas baseadas em teorias de cunho espiritualista e a flagrante ausência de uma proposta de método de pesquisa prática.

Gino Germani lamenta a tendência latino-americana de politizar o âmbito da ciência. Essa politização, segundo ele, se relaciona em larga medida com a inexistência de um campo autônomo para a sociologia. A história e os historiadores, em geral vinculados a uma proposta de construção da nação, teriam efeitos perniciosos na composição de uma análise clara e isenta dos processos argentinos. O curso de História (com exceção daquela pensada por Romero, de cunho social), acabou se configurando como um pólo opositor à proposta de Germani, não apenas no sentido epistemológico mas também, e principalmente, por se mostrar refratário à ideia de que a vocação da Universidade estivesse ligada à formação técnica, baseada no trabalho de campo e longe dos "estudos clássicos" que a tinham caracterizado até então.

Se observarmos os Boletíns del Instituto de Sociologia desses anos de reformulação do instituto, notaremos, a partir da publicação de diversos autores estrangeiros, a proposta clara de fomentar as redes, de lançar num esforço editorial de larga monta que viabilizasse o exercício dessa institucionalização e profissionalização da disciplina. Algumas propostas, no entanto, tais como a vinculação de professores em regime de dedicação exclusiva, não eram prerrogativas unicamente ligadas ao Instituto de Sociologia ${ }^{22}$. Contudo, fomentar uma atividade professoral e exclusiva, para essa nova proposta sociológica, era um ponto de partida para que a pesquisa não se apresentasse mais como um hobbie, "esto equivale a decir que los científicos representan un grupo en sentido sociológico, que existe una comunidad de científicos" (GERMANI, 1966, p. 73).

Para tornar exequivel a proposta do Instituto, contudo, era preciso mão de obra, docentes e alunos dispostos a adquirir um "habitus" específico, uma jogo de linguagem próprio e a uma adesão substantiva a essa nova orientação. Trata-se, de certa forma, de produzir uma "comunidade de significação" a nível continental, baseado na rotinização de tarefas e em uma postura estritamente científica, longe da politização típica das análises essencialistas e românticas que Germani via na história do pensamento argentino.

O próprio Germani, analisando essa tensão, nos aponta que

En la década del 60 observamos una cresciente separación de los grupos que se disputan la legitimidade del saber dentro del âmbito acadêmico, una disputa que no se circunscribe ya a cuestiones metodológicas sino fundamentalmente a

\footnotetext{
${ }^{22}$ Desde a década de 1920 uma sucessão de reformas estatutárias (em larga monta inspirados pelo movimento da Reforma Universitária), já buscava capitanear adesões para a aprovação de uma 'carreira universitária'. Dentre as iniciativas que se contam nas décadas de 1920 e 1930 constam a vinculação de professores substitutos às Catedras, um sistema efetivo de concessão de bolsas e um sistema de ingresso baseado na avaliação dos docentes que favorecesse a incorporação dos egressos da Universidade.
} 
concepciones políticas vinculadas a la función social que debe assumir la ciência y el próprio intelectual (GERMANI, 2010, p. 39).

O Instituto se posiciona, dessa forma, a partir de uma proposta de modernização, distante de um rompimento absoluto. É flagrante a tensão entre um campo autônomo com prestígio específico na universidade e uma tradição especificamente argentina de arenas culturais alheias ao mundo acadêmico, centrada em ambientes privados como os cafés e os salões literários. Essa situação atua como um dificultador da estruturação do campo da sociologia, principalmente porque torna abrangentes demais os limites de prestígio, diluindo assim um capital simbólico que, em tese, deveria ser monopólio da instância universitária.

Em um dos momentos de maior tensão nesses anos iniciais do Instituto, Germani buscou financiamento privado para algumas das pesquisas empíricas do instituto. Tal medida, impopular entre vários setores da própria Faculdade de Filosofia y Letras, foi justificada precisamente a partir da ideia de autonomia universitária, entendida, nesse caso, como autonomia técnica. Do centro de sociologia, dizia-se que não deveria haver interferência política, motivo pelo qual não havia problemas em aceitar o financiamento da fundação Ford, por exemplo. Essa visão bastante particular da autonomia de pesquisa destacou o Instituto de Sociologia dos outros criados nesse mesmo contexto, inclusive demarcando fronteiras específicas de enfrentamento dentro da própria Universidade.

Embora radicalmente ligado a um processo de renovação da universidade como um todo, o prestígio do Instituto teve vida curta, e em nenhum momento uma aceitação unânime de seus pares universitários. A partir de 1964, é possível notar um processo de radicalização e politização dentro da universidade, principalmente por parte de setores do movimento estudantil ligados às alas radicais do peronismo. Nesse ano, a UBA já era chamada de llha Democrática, apontando para um processo sem volta de radicalização e crescente violência política, que iria desembocar no golpe de 1966.

Os conflitos que as propostas de Germani suscitavam, principalmente entre os estudantes, nos ajudam a, recorrendo ao debate Said Bourdieu, matizar o que está sendo pensado quando se fala de autonomia. 0 projeto do sociólogo guarda uma relação mais estreita com a autonomia no sentido de possibilidade de pesquisa do que propriamente uma concepção romântica de autonomia do intelectual como livre pensador. Essa concepção de autonomia, como temos procurado destacar, funcionaria no marco da elaboração de um papel específico para o sociólogo na sociedade argentina, e não equivale ao sentido de "autonomia" que identificamos na proposta de Said, mais conectada à preservação de uma fala individual do sujeito intelectual.

Além da violência que tomava conta da sociedade argentina, a radicalização interna da Universidade também contribui para o paulatino descrédito da proposta empirista e técnica de Germani. As críticas ao projeto do novo Instituto, segundo ele, vinham de uma "elite literária antipositivista, que compartia orientaciones filosóficas y normativas fundadas en la fenomenologia (Scheller), el neotomismo y el 
existencialismo alemán" (GERMANI, 2010, p. 31)23. Somado ao descrédito no plano teórico, a aproximação da Sociologia praticada no Instituto com os paradigmas estruturais funcionalistas das universidades dos Estados Unidos também provocou reações negativas de parte dos setores de esquerda, que viam nessa adesão metodológica uma perniciosa capitulação frente ao imperialismo norte-americano.

Não é demais lembrar, nesse sentido, que os influxos da Revolução Cubana, sistematizados por diversas publicações e plenamente convergentes com o crescimento dos partidos socialistas no continente, dão um novo sentido à ideia de "engajamento" e, principalmente, ao engajamento do intelectual, confrontado nesse momento com polarizações importantes, embasadas em um antiintelectualismo de envergadura global ${ }^{24}$.

Se os setores de esquerda mais radicalizados partiam em defesa da luta armada e, muitas vezes, abandonavam as trincheiras universitárias, em 1966, o golpe militar e o episódio de violência brutal dentro da Universidade que ficou conhecido como "la noche de los bastones largos"25, ajuda a decretar o fim do projeto de Germani enquanto agente estruturador de um campo novo. A ditadura militar que se segue ao golpe, ao contrário do período peronista, não se contentaria com uma adesão formal de docentes e estudantes, e a repressão e violência passam a ser sistêmicas. A pauta da autonomia universitária, nesse contexto, está absolutamente superada pelas iniciativas autoritárias dos governos militares.

Apesar disso, é claramente impossível inutilizar o esforço de criação do Instituto e do campo sociológico levado a cabo por Germani, mesmo tendo em vista a demissão massiva de professores e a volta de uma perspectiva essencialista de cunho nacionalista para a Universidade. Se, por um lado, podemos perceber que o golpe militar e a ditadura subsequente a ele contribuiu para dificultar a sobrevivência de um campo autônomo para o intelectual sociólogo, no sentido em que pontua Bourdieu, por outro lado, a intervenção direta na Universidade contribui para o fortalecimento das redes privadas de apoio mutuo entre os homens de letras, capazes de sustentar, em seu bojo, um espaço para o amateur, para o intelectual crítico.

Consideramos que as tensões supracitadas trazem questionamentos importantes para uma história intelectual que se proponha a pensar as tensões sociais que emergem dos discursos da arena universitária, inclusive em contextos contemporâneos, onde a função pública do intelectual é abertamente relativizada e, em muitos casos, encontra-se em franca oposição aos desejos do mercado editorial. Transitar, como no caso argentino, entre as possibilidades de autonomia intelectual e de autonomia do intelectual nos leva a pensar a construção de redes de prestígio paralelas e conflitantes como um dado fundamental da atividade intelectual que se estabelece a partir da década de 1960 em diversos países da América Latina.

\footnotetext{
${ }^{23} \mathrm{Na}$ biografia intelectual escrita por Ana Germani, a crítica do sociólogo é ainda mais pungente: "según Germani, el triunfo de las corrientes antipositivistas representó um desastre para las ciências del hombre; sus repercusiones negativas transcienderon el campo de la cultura superior y afectaran la vida cotidiana, contribuyendo a la expresión de ideologias irracionalistas y a equivalentes intelectuales de los totalitarismos políticos" (GERMANI, 2004, p. 80).

24 Nesse contexto, a ideia de "engajamento" deixa de sinalizar uma posição ativa de analista da realidade, ligada à uma apropriação da linguagem e da fala pública, e passa a significar, em oposição àquele conceito sartriano de engajamento que havia inspirado os liberais de Sur, uma adesão formal à partidos e instituições de esquerda.

25 O episódio conhecido como La Noche de Los Bastones largos diz respeito à invasão armada, por parte da Polícia Federal Argentina, de 5 Faculdades da Universidade de Buenos Aires, em represália à ocupação que envolvia professores e alunos e que se opunha à intervenção na Universidade.
} 
Talvez um caminho para conjecturar acerca da criação e viabilização de campos de ação pública do intelectual seja a possibilidade de localizar os sujeitos dentro de redes específicas e estruturadas, que não agem como determinantes em ultima instância, mas que circunscrevem as possibilidades de enunciação e circulação dos discursos. Nesse sentido, pensar a autonomia dos intelectuais passa a ser um problema, além de político, também metodológico, que pode ajudar a cotejar a especificidade das redes nacionais a partir de um ponto de vista entrecruzado, que problematize inclusive a universalização perniciosa de alguns discursos nacionais.

Carlos Altamirano, retratando esse problema no caso argentino, salienta uma particularidade importante dessa "arena intelectual", de onde se projetam os discursos sobre a modernidade latinoamericna e argentina, especificamente. Para este autor, a aristocracia desses países havia reservado um espaço para os intelectuais em sua estrutura de poder que se mantém sólida até a década de 1920, coesão que é no entanto parcialmente fracionada com a emergência das propostas de cunho nacional-popular das décadas de 1930 e 1940, o que passa a gerar uma vasta gama de discussões acerca do papel do intelectual naquelas sociedades e de como este poderia posicionar-se politicamente e manter, ainda assim, seus privilégios e seu prestígio enquanto homem de letras.

Pensamos em compreender essas vinculações e jogos de prestígios a partir da proposta de que a lógica dos campos de produção simbólica estão incorporadas em um habitus específico. Esse "sentido do jogo", que funciona quão maior for sua capacidade de passar despercebido, pode nos ajudar a pensar de que forma as disputas epistemológicas dos campos intelectuais não podem obscurecer a visão do analista objetivo às tensões políticas e sociais que delineiam essas disputas supostamente "teóricas". Sendo assim, nos parece viável entender as mediações entre o intelectual e a rede de edição e divulgação na qual está inserido a partir dessas adesões prováveis e presumíveis, que dão espaço a uma alternativa não-mecânica da interpretação das vinculações dos sujeitos à determinado tipo de discurso.

Dessa forma, acreditamos que pensar a ligação dos intelectuais com o espaço público, as tensões entre o amadorismo e o engajamento, os limites da autonomia do campo de produção cultural e a relação dos homens de letras com as instituições são caminhos plausíveis para construir uma análise específica dos problemas concernentes à história intelectual, principalmente quando confrontados com realidades nacionais problemáticas, que se encontram fissuradas pelo aumento progressivo das instâncias de consagração do discurso e um paralelo processo de profissionalização da atividade intelectual, como sugere o caso da Argentina nas décadas de 1950 e 1960.

Se, a título de conclusão, pode parecer paradoxal que as lutas pela profissionalização do campo sociológico na Argentina tenham sido encampadas, em larga medida, por atores que se encaixariam, sem dificuldades, no perfil de "amateurs" proposto por Said, é importante considerar que, por outro lado, as iniciativas operadas a partir do Departamento de Sociologia propunham rompimentos importantes nas hierarquias de prestígio da Faculdad de Filosofia y Letras. Se, durante muitas décadas, as cátedras ligadas aos estudos considerados clássicos (História, Letras Argentinas, Grego, etc) estiveram associadas a uma vocação de "busqueda de las fuentes y los antecedentes históricos nacionales" (BUCHBINDER, 1997, p. 28) indispensáveis à função pedagógica da Universidade, esses setores mais investidos de capital acadêmico 
passam a ser frontalmente questionados, ao menos no que diz respeito à função prática da formação acadêmica.

Não se trata de incorporar apenas um novo ponto de vista, empírico, etnológico ou funcionalista, mas de incorporar à estrutura universitária uma larga gama de procedimentos e redes de prestígio que se geraram e fortaleceram fora da Universidade. Assim, apesar dos questionamentos múltiplos e da hegemonia da teoria da dependência nas análises sociológicas dos anos posteriores à 1966, as disputas internas geradas pela institucionalização da sociologia na Universidade de Buenos Aires contribuíram para a complexificação (e consubstanciada amplificação) das instâncias de enunciação cultural daquele contexto e contribuíram para a criação de um "prestígio universitário" inédito na Argentina, inclusive em termos de inserção numa rede internacional de pesquisa e consagração científica (PEREYRA, 2005).

O conflito para com as disciplinas "canônicas" ou ao menos estruturadas a partir de métodos clássicos, pode nos ajudar a pensar, inclusive, a pertinência da atualíssima discussão entre o espaço do discurso histórico e o espaço do discurso sociológico na América Latina. Embora as colaborações interdisciplinares especialmente fomentadas pelas leituras da Escola dos Annales e da História Quantitativa - sejam praxe dentro dos Institutos de História e Sociologia, é possível, ainda, diagnosticar algumas tensões. As disputas pelas fronteiras interpretativas, no sentido em que pontua Lepenies, entre as duas tendências opostas, operaram uma verdadeira disputa por paradigmas ao longo de todo o século XX, configurando-se um polo fundamental de delimitação de práticas de pesquisas e concessão de prestígio intelectual no campo público.

Ao mesmo tempo não se pode ignorar que a visão de Germani de sociologia como instrumento de planificação é interventora e, assim, defensora do papel publico do intelectual, trata-se de uma intervenção específica, que valoriza aqueles que valorizam as regras de produção internas à disciplina. Nesse sentido, nos parece mais uma vez pertinente levantar uma das questões centrais do debate sobre os intelectuais: como operar dentro das possibilidades híbridas que se encontram entre a solidão (entendida aqui como autonomia e possibilidades reais de "falar a verdade ao poder") e o engajamento, pensado como uma relação de permanente tensão entre a tomada de posição na esfera pública e a preservação do olhar crítico, objetivado e objetivante, capaz de voltar os instrumentos da crítica contra si próprio ${ }^{26}$.

Considerando esses instrumentos analíticos é possível, além disso, dimensionar o alcance dos rompimentos e das iniciativas individuais, como ataques ao campo ou, em maior medida, como ataques que se dirigem à busca de uma melhor posição relativa dentro do campo. Finalmente se, por um lado, nos parecem fundamentais os alertas de Said no que diz respeito ao compromisso crítico, por outro, consideramos que "compreender a gênese social de um campo e aprender aquilo que faz a necessidade específica da crença que o sustenta, do jogo de linguagem que nele se joga, das coisas materiais e simbólicas em jogo que neles se geram, é explicar os atos dos produtores" (BOURDIEU, 1989, p. 70).

\footnotetext{
${ }^{26}$ Seria, na conceitualização de Bourdieu, uma decorrência da ameaça à autonomia da razão por parte dos poderes instituídos,
} que provocariam uma oscilação dos intelectuais entre a "solidão" e o "engajamento", caracterizando sua bi-dimensionalidade. 


\section{Referências}

ALTAMIRANO, C. Ideias para um programa de história intelectual. Tradução de Norberto Guarniello. Buenos Aires: Universidade Nacional de Quilmes, 2007.

BLANCO, A.; JACKSON, L. Sociologia no espelho: ensaístas, cientistas sociais e críticos literários no Brasil e na Argentina (1930-1970). São Paulo: Ed. 34, 2014.

BOBBIO, N. Os intelectuais e o poder. Tradução de Marco Aurélio N. São Paulo: Ed UNESP, 1997.

BOS, J. Les types de marginalisation dans leur relation constitutive au discours. L'Homme et La Société, [S. I.], n. 167-168, 2008.

BOURDIEU, P. Homo academicus. Buenos Aires: Siglo XXI, 2008.

BOURDIEU, P. Intelectuales, política y poder. Buenos Aires: Universidade de Buenos Aires, 2009.

BOURDIEU, P. Meditações pascalianas. Tradução de Sergio Miceli. Rio de Janeiro: Bertrand Brasil, 2001.

BOURDIEU, P. O poder simbólico. Lisboa: Difel, 1989.

BOURDIEU, P.; CHAMBOREDON, J.; PASSERON, J. Ofício de sociólogo: Metodologia da pesquisa na sociologia. Tradução de Guilherme F. Teixeira. Petrópolis: Vozes, 2004.

BUCHBINDER, P. Historia de la Facultad de Filosofia y Letras. Buenos Aires: Universidad de Buenos Aires, 1997.

DONGHI, T. H. História de la Universidad de Buenos Aires. Buenos Aires: Libros de Rojas, 2012.

FIORUCCI, F. El antiperonismo intelectual: de la guerra ideológica a la guerra espiritual. Washington: LASA, 2011.

GERMANI, A. Gino Germani: del antifascismo a la sociologia. Buenos Aires: Taurus, 2004.

GERMANI, G. Estudios sobre sociologia y psicologia social. Buenos Aires: Paydós, 1966.

GERMANI, G. La sociedad en cuestión: antologia comentada coordenada por Julian Rebón. Buenos Aires: CLASCO, 2010.

GRAMSCI, A. Os intelectuais e a organização da cultura. Rio de Janeiro: Civilização Brasileira,1982. 
LACAPRA, D. Intellectual history and it's ways. The American Historical Review, Bloomington, v. 92, n. 2, p. 425-439, 1992.

LEPENIES, Wolf. As três culturas. São Paulo: EDUSP, 1996.

MONEGAL, E. R. El juicio de los parricidas. Buenos Aires: Deucalion, 1956.

NEIBURG, Federico. Os intelectuais e a invenção do peronismo. São Paulo: EDUSP, 1997.

NIZAN, P. Les chiens de garde. Paris: François Maspero, 1960.

PEREYRA, D. International networks and the institutionalisation of sociology in Argentina (1940 -1963). Brighton: School of Sciences and Cultural Studiesm University of Sussex at Brighton, 2005.

REMOND, R. Por uma história política. Rio de Janeiro: FGV, 1996.

RICCONO, G. Universidad y peronismo: batalla de imágenes. In: JORNADAS DE SOCIOLOGÍA DE LA UNIVERSIDAD NACIONAL DE LA PLATA, 7., 2012, La Plata. Actas... La Plata, 2012. Disponível em: <http://sedici.unlp.edu.ar/handle/ 10915/31375>. Acesso em: 5 maio 2016.

RUBINICH, L. Los sociólogos intelectuales: cuatro notas sobre la sociologia en los años sesenta. Apuntes de Investigación del CECyP, Buenos Aires, n. 4, jun. 2015.

SAID, E. Orientalismo: o oriente como invenção do ocidente. São Paulo: Companhia de Bolso, 2007.

SAID, E. Representações do intelectual. Tradução de Milton Hatoum. São Paulo: Companhia das Letras, 2005.

SAPIRO, G. Elementos para uma história do processo de autonomização: o exemplo do campo literário francês. Tempo Social, São Paulo, v. 16, n. 1, p. 93-105, jul. 2004.

SARTRE, J. P. Em defesa dos intelectuais. Tradução de Sergio de Paula. São Paulo: Ática, 1994.

SIGAL, S. Le rôle politique des intellectuels en amerique latine: la derive des intellectuels en Argentine. Paris: L'Harmattan, 1996.

TERÁN, Oscar. Ideas e intelectuales en la Argentina, 1880-198. In: TERÁN, O. (Org.). Ideas en el siglo intelectuales y cultura en el siglo XX latinoamericano. Buenos Aires: SigloXXI, 2004.

Recebido em 19/06/2016 - Aprovado em 30/01/2016. 